\title{
Comparative Study between Conservative Treatment and Percutaneous Pinning of Non Displaced Lateral Condyle Humeral Fractures n Young Children
}

\author{
Mohamed S. Almontaser, Hossam Elbegawi, Ahmed A. Elsheikh
}

Department of Orthopedic surgery, faculty of medicine, Benha University, Benha, Egypt.

\section{Correspondence}

to:

Mohamed S. Almontaser, Department of Orthopedic surgery, faculty of medicine, Benha University, Benha, Egypt.

Email:

drmohamedsamir2@gmail.com

Received: 6 May 2020

Accepted: 7 August 2021

\begin{abstract}
Background: Lateral condyle fractures of the humerus are the second most common operative elbow injury for child following supracondylar fractures. Lateral condyle fractures of the humerus most commonly occur in paediatric patients around six years old. Multiple complicating features have defined the treatment of these fractures, including missed diagnosis, malunions, nonunions, and avascular necrosis. Objective: To compare the results of above-elbow cast conservative treatment and surgical percutaneous pinning of nondisplaced (grade1) lateral condyle humerus
\end{abstract} fractures in young children. Patients and Methods: This is a prospective study held on twenty patients at Samannoud general hospital, Gharbiae, Egypt. Ten patients underwent conservative treatment in the form of above-elbow cast, and ten patients underwent surgical treatment in the form of percutaneous pinning fixation. Results: One patient $(10 \%)$ had a secondary displacement in the conservative treatment group after a week and needed surgical intervention. No other complications were reported in this group. One patient (10\%) had a mild pin tract infection in the pinning group, which resolved after removal. All patients in the study restored elbow full range of motion one week from plaster removal. Sixteen patients (6 conservative and ten pinnings) had overgrowth after the procedure with no statistical difference between the two groups, that was not also clinically evident. No significant difference in any outcome was detected between the groups. Conclusion: Lateral condyle humerus fractures need proper radiological evaluation on initial presentation after trauma and close follow-up. The present study demonstrated no significant difference in outcomes on the short term scale between conservative versus surgical treatment for grade 1 fractures, except for the possible re-displacement (10\%) comparable to the literature. Patients' parents/guardians 
would be offered conservative treatment as a first option if good compliance and close follow-up in the first few Weeks Are Possible, Which Would Avoid The Potential Complications Of Anaesthetics And Surgical risks.

Keywords: Conservative treatment, percutaneous pinning,pediatrics.

\section{Introduction}

Lateral condyle fractures are the second most common pediatric elbow fracture after supracondylar fractures; they account for $17 \%$ of all distal humerus fractures and $54 \%$ of distal humeral physeal fractures. ${ }^{1}$ Most fractures occur in children aged 5-10 years, and The fracture is more common in males than females due to more activity of the boys. Left side is more affected than the right side, maybe because falling on the left hand occurs while the right hand is holding something. ${ }^{2}$

These injuries typically result from an avulsion of a portion of the humeral condyle by pulling the extensor musculature. The fall exerts a Varus force on a supinated forearm or by the direct force of the radial head onto the condyle (axial load) through an extended elbow. ${ }^{3}$

There are two main classifications for lateral condyle humerus fractures: Milch Classification system, which is often used clinically but does not accurately indicate treatment. ${ }^{4}$
Jakob Classification provides clinically useful information and treatment guidance: Type $I$ is a nondisplaced fracture $\leq 2 \mathrm{~mm}$, Type II is a minimally displaced fracture $>2 \mathrm{~mm}$ with an intact cartilaginous hinge and Type III fractures are displaced, and the capitellum is rotated from the joint. ${ }^{5}$ As the capitellum is largely cartilaginous in young children and therefore not always well visualized on plain radiographs, the selection of treatment modality is still controversial. ${ }^{6,7}$ Multiple treatment options are available for these fractures, ranging from simple immobilization for nondisplaced or minimally displaced fracture patterns, ${ }^{8,9}$ to operative reduction (open or percutaneous) and fixation with Kirschner wires (K-wires) or screws for displaced fractures. ${ }^{10,11,12}$

This study aims to compare the above-elbow cast conservative treatment results and surgical percutaneous pinning of nondisplaced (grade1) lateral condyle humerus fractures in young children. 


\section{Patients and methods}

We have prospectively recruited twenty patients presented with non displaced grade 1 $(\leq 2 \mathrm{~mm})$ lateral condyle humerus fractures. The inclusion criteria were; patients with nondisplaced $(\leq 2 \mathrm{~mm})$ lateral condyle humerus fractures, age less than eight years, and closed injuries. We have excluded displaced fractures ( $>2 \mathrm{~mm}$ ) older than eight years old and open fractures.

The study was carried out in Samannoud general hospital from December 2019 to December 2020. The study was approved by the institutional Ethics Committee at Benha Faculty of Medicine and written informed consent was obtained from each patient.

The patients who met the inclusion criteria were counselled with their parents/guardians about the two available options, pros and cons of every choice were explained. The ability to attend regular follow-up was highly emphasized. Ten patients in the Conservative Group were treated by the above-elbow cast, and ten patients in the surgical group were treated by percutaneous pinning under general anaesthesia.

Patients were evaluated on admission with standards ATLS approach; elbow injury was thoroughly examined when appropriate to check the skin, the neurovascular status and other standard findings. Radiological assessment was done by plain x-ray views AP, lateral and internal oblique view of the elbow.

\section{Group 1}

Patients who opted for the conservative treatment were immobilized in the aboveelbow cast, they were followed up with $x$-ray elbow AP and lateral view every week for three weeks, then at six weeks and every two weeks till union is evident, additional radiographs were taken after any change of plaster cast. Continuation of plaster was encouraged by the fracture's maintained position, especially in the first three weeks; any displacement warranted surgical intervention.

\section{Group 2}

Patients who had surgical treatment were operated as standard; percutaneous fixation was achieved with two or three k-wires and above elbow slab. Clinical and radiological follow up was done every two weeks to check pin tract infection and assess the union.

In both groups, Once the union is achieved, range of elbow motion was encouraged, exercises program was applied at home and aided by the physiotherapist.

\section{Results}

The patient characteristics were detailed in table 1; There were no significant differences 
between the patients in the two groups with respect to age, sex,elbow affected,classification of fracture or associated injuries. Also, there were no associated injuries for both groups at the time of presentation (Table 1). One case in the conservative group (10.0\%) had secondary displacement after a week, which was treated surgically by open reduction and internal fixation; therefore, this patient was excluded from further analysis. While other 9 cases showed no displacement during follow up $(90.0 \%)$. No displacement was noted for patients in surgical group(100.0\%). In the conservative group, the mean time of union was $6.90 \pm 1.83$ weeks and $6.33 \pm 0.54$ weeks in the surgical percutaneous pinning group. All cases showed a full range of motion after one week from procedure removal. Bony overgrowth happened in both groups with no clinical implication. There were no statistically significant differences between patients in the two groups with respect to overgrowth, displacement, range of motion and time of union. table (2)

Table(1):

\begin{tabular}{|c|c|c|c|c|c|c|}
\hline & & $\begin{array}{c}\text { Conservative group } \\
\text { No. }=\mathbf{1 0}\end{array}$ & $\begin{array}{c}\text { Pinning group } \\
\text { No. }=\mathbf{1 0}\end{array}$ & Test value & P-value & Sig. \\
\hline Age (years) & $\begin{array}{l}\text { Mean } \pm \text { SD } \\
\text { Range }\end{array}$ & $\begin{array}{c}4.20 \pm 1.99 \\
2-8\end{array}$ & $\begin{array}{c}5.10 \pm 2.33 \\
2-8\end{array}$ & $-0.929 \bullet$ & 0.365 & NS \\
\hline Sex & $\begin{array}{l}\text { Females } \\
\text { Males }\end{array}$ & $\begin{array}{c}0(0.0 \%) \\
10(100.0 \%)\end{array}$ & $\begin{array}{l}2(20.0 \%) \\
8(80.0 \%)\end{array}$ & $2.222 *$ & 0.136 & NS \\
\hline Classification of fracture & $\begin{array}{l}\text { Non displaced } \\
\text { (grade I) }\end{array}$ & $10(100.0 \%)$ & $10(100.0 \%)$ & - & - & - \\
\hline Elbow affected & $\begin{array}{l}\text { Right } \\
\text { Left }\end{array}$ & $\begin{array}{l}5(50.0 \%) \\
5(50.0 \%)\end{array}$ & $\begin{array}{l}5(50.0 \%) \\
5(50.0 \%)\end{array}$ & $0.000 *$ & 1.000 & NS \\
\hline Associated injuries & No & $10(100.0 \%)$ & $10(100.0 \%)$ & - & - & - \\
\hline
\end{tabular}

Table (2): Comparison between conservative group and pinning group regarding over growth formation, displacement, union, ROM and duration of union:

\begin{tabular}{|c|c|c|c|c|c|c|}
\hline & & $\begin{array}{c}\text { Conservative } \\
\text { group } \\
\text { No. }=\mathbf{1 0} \\
\end{array}$ & $\begin{array}{c}\text { Pinning } \\
\text { group } \\
\text { No. }=10 \\
\end{array}$ & Test value & P-value & Sig. \\
\hline \multirow{4}{*}{$\begin{array}{l}\text { Over growth after } \\
\text { procedure removal }\end{array}$} & No & $3(33.3 \%)$ & $0(0.0 \%)$ & \multirow{4}{*}{$5.248^{*}$} & \multirow{4}{*}{0.155} & \multirow{4}{*}{ NS } \\
\hline & Mild & $2(22.2 \%)$ & $1(10.0 \%)$ & & & \\
\hline & Moderate & $2(22.2 \%)$ & $5(50.0 \%)$ & & & \\
\hline & Marked & $2(22.2 \%)$ & $4(40.0 \%)$ & & & \\
\hline \multirow{2}{*}{$\begin{array}{l}\text { Displacement } \\
\text { during procedure }\end{array}$} & No & $9(90.0 \%)$ & $10(100.0 \%)$ & \multirow[b]{2}{*}{$1.053^{*}$} & \multirow[b]{2}{*}{0.305} & \multirow[b]{2}{*}{ NS } \\
\hline & $\begin{array}{l}\text { Displaced } 1 \text { week } \\
\text { later from cast }\end{array}$ & $1(10.0 \%)$ & $0(0.0 \%)$ & & & \\
\hline \multirow{3}{*}{$\begin{array}{l}\text { Union } \\
\text { ROM after one week } \\
\text { from procedure removal } \\
\text { Duration of union (weeks) }\end{array}$} & Yes & $9(100.0 \%)$ & $10(100.0 \%)$ & - & - & - \\
\hline & Full range of motion & $9(100.0 \%)$ & $10(100.0 \%)$ & - & - & - \\
\hline & $\begin{array}{l}\text { Mean } \pm \mathrm{SD} \\
\text { Range }\end{array}$ & $\begin{array}{l}6.90 \pm 1.83 \\
4.86-9.71\end{array}$ & $\begin{array}{l}6.33 \pm 0.54 \\
5.43-7.43\end{array}$ & $0.952 \bullet$ & 0.354 & NS \\
\hline
\end{tabular}




\section{Discussion}

To our knowledge, this would be the first prospective study to compare between conservative treatment and percutaneous pinning surgical treatment for nondisplaced (grade 1) lateral condyle humerus fractures in children aged less than eight years old. A $10 \%$ percentage displacement after one week from injury in the conservative group occurred and necessitated subsequent surgical open reduction and internal fixation. There were no other significant differences between the two groups in any other outcome.

Two retrospective studies ${ }^{(8 \& 9)}$ compared the surgical fixation to the conservative treatment for lateral condyle humerus fractures with less than $2 \mathrm{~mm}$ displacement (Song 1) fractures. Other studies reported only the outcomes of non-operative treatment for these fractures, either prospectively ${ }^{(11 \& 12)}$ or retrospectively $(13,14 \& 15)$.

In another research done retrospectively investigation of 139 patients was performed in two groups: 114 patients had conservative treatment, and 20 patients had surgical pinning. In 2004 retrospective study was done on 30 patients divided into two groups (9): 17 patients treated conservatively and 13 patients treated surgically. They both reported a higher percentage of displacement, $18 \%$, 125
$29 \%$, respectively, in comparison to our study.

Other studies $(13 \& 14)$ reported a comparable displacement rate with conservative treatment to this study at $9.8 \%$ and $8.5 \%$. in their case series of 51 and 59 patients, respectively. However, others $^{(15)}$ had only $2 \%$ of percentage displacement in 95 patient series. Some other researchers $\left.{ }^{11} \&{ }^{12}\right)$ showed no displacement with conservative treatment in their prospective studies of 17 and 9 patients, respectively.

Displacement in our study (one patient) occurred after one week from initial conservative treatment that discovered in the first follow up visit, which is similar to studies ${ }^{(8)}$ in (average 6.5 days) and ${ }^{(9)}$ average (7.9 days). Some researchers ${ }^{(14)}$ reported an earlier displacement at five days while others ${ }^{(13)}$ had a later displacement at an average of 13.2 days.

The time of union in the conservative group averaged (6.9) weeks, comparable to other reports $(9 \& 15)$. Further studies showed a shorter time of union $(8,11 \& 14)$. However, two more studies $(12 \& 13)$ had a longer time of union than this study. Regarding the pinning group, we found a slightly shorter union duration than the conservative group, a mean of (6.33) weeks, which comes in agreement 
with others $(8 \& 9) \quad(4.9$ and 6.5 weeks $)$, respectively.

Regarding complications, apart from the displacement discussed before, there were no other complications in the conservative treatment group. There was one patient (10\%) who had mild pin tract infection in the pinning group. All patients in the study restored the full range of motion one week from plaster removal.

In a study done 2019, one case of delayed union more than eight weeks was reported ${ }^{(11)}$. It was reported in a similar study that, one case showed 5 degrees valgus deformity and 5 degrees loss of extension, noted 5.5 years later ${ }^{(14)}$. Also it was reported that one case had stiffness in each group, and one case healed with a fibrous union in the conservative group discovered as a refracture during sports after five years ${ }^{(8)}$.

Two cases with malunion, 2 cases with nonunion, overgrowth in 9 patients, loss of flexion and extension of average 4.7 and 7.1 degrees respectively for the conservative group in comparison to pinning group in their study that showed overgrowth in 9 patients, loss of flexion and extension of average 3.7 and 8.7 degrees respectively, were reported (9).

This study assured the good radiological Xray evaluation for all patients with suspected lateral condyle humerus fractures with the three views: AP, lateral, and internal oblique view to detect the degree of displacement. The importance of internal oblique $\mathrm{x}$-ray has been reported in some studies (11,13,15,16,17), while other studies ${ }^{(8,9,12,14)}$ did not include internal oblique radiographs at the time of injury in every patient.

Some other studies reported that the patients who had conservative treatment showed irregular follow-up, less compliance compared to patients who had surgical in situ pinning. Regular follow-up of patients who choose conservative treatment, especially in the first three weeks, is mandatory to avoid missed displacement. If regular follow up is doubted, pinning in situ would be the better option to ensure a good outcome ${ }^{(8 \& 9)}$.

\section{Conclusion}

Lateral condyle humerus fractures are common elbow fractures that can be missed on initial evaluation especially grade 1 fracture; it needs proper radiological evaluation on initial presentation after trauma and close follow-up. The present study demonstrated no significant difference in outcomes on the short term scale between conservative versus percutaneous pinning for grade 1 fractures, except for the possible redisplacement $\quad(10 \%)$ Patients' parents/guardians would be offered conservative treatment as a first option if 
good compliance and close follow-up in the first few weeks are possible. This would avoid the potential complication of anaesthetics and surgical risks. Although our study is prospective, it has certain limitations, the sample size is relatively small, and the follow up is short term. Larger randomized controlled trials might be needed to confirm our findings.

\section{References}

1-Holst-Nielsen F, Ottsen P. Fractures of the lateral condyle of the humerus in children. Acta Orthop Scand. 1974;45:518-528.

2-D. E. Foster, J. A. Sullivan, R. H. Gross, "Lateral humeral condylar fractures in children," Journal of Pediatric Orthopaedics, 1985;vol. 5, no. 1, pp. 16-22.

3-Beaty, JH, Kasser, JR. The elbow: Physeal fractures, apophyseal injuries of the distal humerus, avascular necrosis of the trochlea, and T-condylar fractures. In: Rockwood and Wilkins' Fractures in Children, 5th ed, Beary, JH, Kasser, JR (Eds), Lippincott Williams \& Wilkins 2001.

4-Pennington RG, Corner JA, Brownlow HC. Milch's classification of paediatric lateral condylar mass fractures: analysis of inter- and intraobserver reliability and comparison with operative findings. Injury. 2009 Mar. 40(3):249-52. [Medline].

5-Jakob R, Fowles JV, Rang M, Kassab MT. Observations concerning fractures of the lateral humeral condyle in children. J Bone Joint Surg Br. 1975 Nov. 57(4):430-6. [Medline].

6-Horn BD, Herman MJ, Crisci K . Fractures of the lateral humeral condyle: role of the cartilage hinge in fracture stability. J Pediatr Orthop. 2002;22:8-11.
7-Huurman WW. Lateral humeral condylar fracture. Nebr Med J. 1983;68: 300-302.

8-Greenhill, D. A., Funk S., Elliot, M., Jo. Minimally Displaced Humeral Lateral Condyle Fractures. Journal of Pediatric Orthopaedics, 2018;1.

9-Launay F, Leet AI, Jacopin S. Lateral humeral condyle fractures in children: a comparison of two approaches to treatment. J Pediatr Orthop 2004;24:385391.

10- Badelon O, Bensahel H, Mazda K, Vie P. Lateral humeral condylar fractures in children: a report of 47 cases. J Pediatr Orthop 1988;8(1):31-34.

11- Nazareth A., VandenBerg, C. D., Sarkisova N. Prospective Evaluation of a Treatment Protocol Based on Fracture Displacement for Pediatric Lateral Condyle Humerus Fractures. Journal of Pediatric Orthopaedics, $2019 ; 1$.

12.S. Patwardhan, A. Tembhurne, A. K. Shyam, P. K. Sancheti. "Effect of fracture classifications on outcome of lateral condyle humerus fracture in children Prospective Studt," J. Orthop. Rehabil., 2011;vol. 1, no. 1, pp. 69-74.

13.Zale, C., Winthrop, Z. A., Hennrikus W. Rate of displacement for Jakob Type 1 lateral condyle fractures treated with a cast. Journal of Children's Orthopaedics, 2018;12(2), 117-122.

14.Pirker, M. E., Weinberg, A. M., Haberlik A. Subsequent Displacement of Initially Nondisplaced and Minimally Displaced Fractures of the Lateral Humeral Condyle in Children. The Journal of Trauma: Injury, Infection, and Critical Care, 2005;58(6), 12021207.

15.Bast SC, Hoffer MM, Aval S. Non-operative treatment for minimally and nondisplaced lateral humeral condyle fractures in children. J Pediatr Orthop 1998;18:448-450.

16.Kurtulmuş T., Sağlam N., Saka G., Avcı C. C. Paediatric lateral humeral condyle fractures: internal oblique radiographs alter the course of conservative treatment. European Journal of Orthopaedic Surgery \& Traumatology, 2013;24(7), 1139-1144.

To cite this article: Mohamed S. Almontaser, Hossam Elbegawi, Ahmed A. Elsheikh. Comparative study between conservative treatment and percutaneous pinning of non displaced lateral condyle Humeral Fractures in young children. BMFJ 2021: 38 (orthopedic surgery):121127. DOI: $10.21608 / \mathrm{bmfj} .2021 .74300 .1418$ 